\title{
New Fellows for 2008
}

\section{John Barnett}

Published online: 12 September 2008

(C) Springer-Verlag 2008

\section{Erratum to: Wood Sci Technol \\ DOI 10.1007/s00226-008-0210-9}

Due to a processing error, a second author (E. Rieber) was erroneously included in the HTML version of this article.

The only author is John Barnett. 